\title{
Arranjo espacial de plantas de milho em sistema plantio direto
}

\author{
Francisco R. da S. Pereira ${ }^{1}$, Simério C. S. Cruz ${ }^{1}$, Abel W. de Albuquerque ${ }^{2}$, José R. Santos ${ }^{2} \&$ Edson T. da Silva ${ }^{3}$
}

\section{RESUMO}

Práticas de manejo que aumentem a população de plantas e reduzam o espaçamento através de arrajamento espacial podem, desde que bem planejadas, podem ser uma excelente oportunidade para que o produtor aumente a sua rentabilidade. Neste trabalho, o objetivo primordial foi avaliar os efeitos da variação da distribuição espacial de plantas em dois híbridos de milho cultivados em Sistema Plantio Direto (SPD) sobre os componentes de produção. O estudo foi desenvolvido no CECA/UFAL. Os tratamentos consistiram no cultivo dos híbridos de milho FORT e AGN 30A00, nos espaçamentos 0,80 e 0,40 m e submetidos às populações de 60.000 e 70.000 plantas ha- ${ }^{-1}$. O delineamento estatístico foi o de blocos casualisados em esquema fatorial $(2 \times 2 \times 2)$, com três repetições. A partir dos resultados obtidos foi possível concluir que nem a redução do espaçamento nem o aumento da densidade de plantas, como práticas isoladas, proporcionaram incremento no rendimento de grãos, para as cultivares testadas; entretanto, a combinação da redução no espaçamento com o aumento na população de plantas resultou em significativo incremento na produtividade de grãos do híbrido FORT.

Palavras-chave: cultivares, espaçamento entre linhas, população de plantas

\section{Spatial arrangement of corn plants in a no-tillage system}

\begin{abstract}
The interaction of management practices that increases plant density and reduces row spacing by spatial arrangement, if well planned, can be an excellent opportunity for the producers to increase their profitability. The objective of this study was to evaluate the variation effects of plant spatial distribution in two maize hybrids cultivated in a no-tillage system on the production components. The study was conducted in the CECA/UFAL. The treatments consisted of the cultivation of two hybrids of maize, FORT and AGN 30A00, in row spacings of 0.80 and $0.40 \mathrm{~m}$ and with plant densities of 60,000 and 70,000 plants ha ${ }^{-1}$. The statistical design was randomized blocks in a $2 \times 2 \times 2$ factorial scheme, with three replications. From the results obtained, it may be concluded that neither the row spacing reduction nor plant density increase, as isolated practices, do not increase grain yield in the tested cultivars. The association of the reduction in row spacing and increase in plant population resulted in significant gain in grain productivity for the hybrid FORT.
\end{abstract}

Key words: cultivars, row spacing, plant density

1 Doutorando FCA/UNESP, Fazenda Experimental Lageado, Bairro Jardim Paraíso, CP 237, CEP 18603-970, Botucatu, SP. Fone: (14) $3811-7132$. E-mail: pereirafrs@hotmail.com

${ }^{2}$ CECA/UFAL, Fone: (82) 3261-1776, E-mail: awa@fapeal.br; santosjr2002@yahoo.com.br

${ }_{3}^{3}$ Mestrando CECA/UFAL, Campos Delza Gitai, km 85, CEP 57100-000, Rio Largo, AL. Fone: (82) 9922-6828. E-mail: edsonets@gmail.com 


\section{INTRODUÇÃO}

A necessidade de melhorar o nível tecnológico da cultura do milho no estado de Alagoas é urgente. O estado apresenta uma das produtividades médias mais baixas do Brasil, que acarreta grandes perdas de divisas devido ao aumento da demanda interna e ao elevado custo de importação desse cereal, de outros Estados.

Várias causas contribuem para a obtenção desses baixos rendimentos destacando-se principalmente o uso de cultivares com baixo potencial produtivo, deficiência na disponibilidade de água e nutrientes no solo, manejo incorreto do solo e utilização inadequada de densidade de semeadura (Silva et al., 2003).

Uma das técnicas que vêm sendo pesquisadas com sucesso no Estado de Alagoas é o Sistema Plantio Direto, que proporciona incrementos cada vez maiores no rendimento da cultura. Silva et al. (2005), comparando o plantio direto com sistemas de manejo de cultivo mínimo e convencional, em Alagoas, observaram superioridade deste sistema em relação aos sistemas tradicionais, constatando ser viável a sua implantação.

Aliada ao sistema de plantio direto, a redefinição do arranjo espacial de plantas, através da diminuição do espaçamento entre fileiras e/ou aumento da densidade populacional, pode ser uma excelente oportunidade para que o produtor aumente a sua rentabilidade sem custos adicionais.

A associação entre o arranjo de plantas e o aumento da produtividade de grãos de milho tem sido freqüentemente reportada na literatura (Duvick \& Cassan, 1999; Tollenaar \& Wu, 1999; Sangoi et al., 2002; Tollenaar \& Lee, 2002). Plantas espaçadas de forma eqüidistante competem minimamente por nutrientes, luz e outros fatores; contudo, devido à interação, o efeito positivo da redução do espaçamento entre linhas sobre o rendimento de grãos se manifesta mais claramente quando são utilizadas altas densidades porém os resultados ainda não são consensuais, já que as condições ambientais e os genótipos variam entre os locais (Sangoi et al., 2004).

De maneira geral, híbridos mais precoces, com menor exigência em soma térmica para florescer, apresentam menor área foliar por planta e menor sombreamento do dossel da cultura; portanto, requerem maior densidade de plantas em relação aos de ciclo normal, para atingir seu potencial de rendimento (Sangoi, 2001).

A arquitetura da planta das cultivares de milho também interfere na qualidade da luz que penetra no dossel e, conseqüentemente, na resposta à densidade de plantas (Kasperbauer \& Karlen, 1994). O desenvolvimento de genótipos com menor número de folhas, folhas mais eretas e menor área foliar, minimiza a competição entre plantas (Almeida et al., 2000); além disso, o ambiente também impõe forte influência na escolha da densidade ideal.

Supõe-se, neste trabalho, que o aumento na quantidade de plantas por hectare, associado à diminuição no espaçamento entre fileiras nas condições edafoclimáticas do Estado de Alagoas, se traduz em maiores rendimentos para a cultura do milho cultivado no Sistema Plantio Direto.
Objetivou-se, assim, avaliar os efeitos da variação da distribuição espacial de plantas em diferentes híbridos de milho cultivados em Sistema Plantio Direto sobre os componentes de produção e produtividade.

\section{MATERIAL E MÉTODOS}

O estudo foi desenvolvido na Área Experimental do Campus Delza Gitaí, pertencente ao Centro de Ciências Agrárias - CECA, da Universidade Federal de Alagoas - UFAL, no município de Rio Largo, AL. As coordenadas geográficas de referência são: Latitude Sul 9०29' 45” e Longitude Oeste $35^{\circ} 49^{\prime}$ 54”. A altitude do local do experimento é $165 \mathrm{~m}$ com 3\% de declividade.

O solo onde se instalaram as parcelas experimentais foi classificado como Latossolo Amarelo coeso distrófico (EMBRAPA, 1999), cujas características químicas, determinadas analiticamente, se encontram na Tabela 1.

Tabela 1. Análise química do solo na profundidade $0-20 \mathrm{~cm}$, amostrado antes da instalação do experimento

\begin{tabular}{|c|c|c|c|c|c|c|c|c|}
\hline \multirow{2}{*}{$\begin{array}{c}\mathrm{pH} \\
\mathrm{H}_{2} \mathrm{O}\end{array}$} & \multirow{2}{*}{$\underset{\mathrm{g} \mathrm{dm}}{\mathrm{MO}}$} & \multirow{2}{*}{$\stackrel{* P}{\mathrm{mg} \mathrm{dm}-3}$} & $\mathrm{H}+\mathrm{Al}$ & K & $\mathrm{Ca}$ & Mg & $\mathrm{T}$ & \multirow{2}{*}{$\begin{array}{l}\mathbf{V} \\
\%\end{array}$} \\
\hline & & & \multicolumn{5}{|c|}{$\mathrm{cmol}_{\mathrm{C}} \mathrm{dm}^{-3}$} & \\
\hline 5,5 & 14 & 15,1 & 3,0 & 0,1 & 0,9 & 0,6 & 4,6 & 35 \\
\hline
\end{tabular}

As análises de solo foram realizadas no Laboratório de Solos e Análise de Produtos Agropecuários do Centro de Ciências Agrárias/UFAL; o clima, de acordo com a classificação de Koeppen, é do tipo As, tropical chuvoso, com verões secos.

Os tratamentos consistiram no cultivo de dois híbridos de milho, FORT e AGN 30A00, semeados em Sistema Plantio Direto, nos espaçamentos 0,80 e 0,40 m e submetidos às populações de 60.000 e 70.000 plantas ha-1 ${ }^{-1}$ Utilizou-se o delineamento estatístico em blocos casualisados em esquema fatorial ( 2 x 2 x 2), com três repetições, em que a área de cada parcela foi de $32 \mathrm{~m}^{2}$, que se compunha de quatro linhas no espaçamento de $0,80 \mathrm{~m}$, e oito linhas no espaçamento de 0,40 m, cada linha com $10 \mathrm{~m}$ de comprimento.

A escolha das cultivares se deu em função de suas características. O híbrido simples FORT é de ciclo precoce, porte médio, com folhas semi-eretas e a população final de plantas recomendada na colheita é de 70.000 plantas ha-1 ${ }^{-1}$ quando irrigado; já o também híbrido simples AGN 30A00, é de ciclo superprecoce, porte baixo, folhas eretas e recomendação de população de 75.000 plantas ha-1.

Antes da instalação do experimento a vegetação de pousio foi dessecada, utilizando-se $3,0 \mathrm{~kg} \mathrm{ha}^{-1}$ do herbicida Glyfosate e o solo recebeu 2 Mg de calcário, aplicados na superfície, visando elevar a saturação por bases para 70\%; dois meses após a calagem se implantaram os tratamentos.

Por ocasião da semeadura, em 20/10/2004, utilizaram-se 30, 120 e $60 \mathrm{~kg} \mathrm{ha}^{-1}$ de $\mathrm{N}, \mathrm{P}_{2} \mathrm{O}_{5}$ e $\mathrm{K}_{2} \mathrm{O}$ e, como fontes, sulfato de amônio, superfosfato simples e cloreto de potássio, respectivamente. Na adubação de cobertura aplicaram-se 120 kg ha-1 
de $\mathrm{N}$ na forma de sulfato de amônio durante o estádio fenológico 1 , ou seja, quando as plantas se encontravam com quatro folhas totalmente expandidas (Fancelli, 1986).

O milho foi semeado através de uma semeadora pneumática, de tração tratorizada, com quatro linhas individuais, espaçadas $0,80 \mathrm{~m}$ ou $0,40 \mathrm{~m}$, conforme o tratamento. A semeadora foi regulada para distribuir 5,2 e 2,6 sementes por metro linear, nos espaçamentos de $0,80 \mathrm{~m}$ e $0,40 \mathrm{~m}$ respectivamente, para estabelecimento da população de 60.000 plantas ha $^{-1}$ e 6 e 3 sementes por metro linear, nos espaçamentos de 0,80 m e 0,40 m, respectivamente, para a densidade de plantio de 70.000 plantas ha-1 ${ }^{-1}$ Durante o estádio fenológico 1 realizou-se o desbaste para o ajuste da população, para 60.000 e 70.000 plantas ha-1.

Como o experimento foi instalado em época atípica à produção de milho no Estado de Alagoas, sentiu-se a necessidade de suplementação de água via irrigação em todos os estádios de desenvolvimento da cultura, em que a mesma foi determinada com base na evapotranspiração da cultura (ETc) e expressa em milímetros por dia $\left(\mathrm{mm} \mathrm{d}^{-1}\right)$; esta suplementação se fez oportuna visto que, neste período, a precipitação pluviométrica da região não atendia às exigências hídricas da cultura (Tabela 2).

Tabela 2. Precipitação pluviométrica registrada na área experimental do Centro de Ciência Agrárias-UFAL, no período de outubro de 2004 a fevereiro de 2005

\begin{tabular}{lc}
\hline Meses & Precipitação (mm mês $\left.{ }^{-1}\right)$ \\
Outubro & 29 \\
Novembro & 25 \\
Dezembro & 08 \\
Janeiro & 32 \\
Fevereiro & 54 \\
\hline
\end{tabular}

Fonte: Estação Agrometeorológica automática CECA-UFAL

Toda a água foi fornecida por meio de um sistema de aspersão convencional com aspessores de pressão de serviço média (20 m.c.a), tipo rotativo, movido por impacto do braço oscilante, constituído de dois bocais; a freqüência de irrigação foi determinada pela relação entre a lâmina líquida fornecida, e a evapotranspiração da cultura do milho, na fase de maior índice de área foliar (Estádio fenológico 4), ou seja, com uma lâmina liquida fornecida de $12 \mathrm{~mm}$ e uma ETc de 4,48 $\mathrm{mm} \mathrm{d}^{-1}$ (Teodoro, 2003), preconizando-se uma freqüência ou turno de rega de 2,67 dias.

Realizou-se o controle de plantas daninhas com a aplicação de herbicidas de manejo e 3,5 L ha-1 da mistura Glyfosate antes da semeadura do milho e $7 \mathrm{~L} \mathrm{ha}^{-1}$ do herbicida Alachlor + Simazina, em pós-emergência, 7 dias depois da semeadura; no controle de pragas foram utilizados $75 \mathrm{~mL} \mathrm{ha}^{-1}$ do inseticida Deltamethrin e as formigas controladas preventivamente, com uso de formicidas granulados.

A colheita foi efetuada aos 110 dias após a semeadura, ocasião em que se avaliaram os componentes da produção: número de plantas por hectare, número de espigas por hectare, comprimento da espiga, número de fileiras de grãos por espiga e massa de 1000 grãos. A produtividade de grãos foi estimada pela massa de grãos obtida em 12,8 $\mathrm{m}^{2}$. Os componentes foram definidos colhendo-se todas as espigas da área útil da parcela, que se compunha de duas linhas de oito metros cada uma, no caso do espaçamento de $0,80 \mathrm{~m}$ e quatro linhas no espaçamento de 0,40 m perfazendo uma área 12,8 m² (1,6 x 8 m).

Os dados originais foram submetidos a análise de variância a 5\% de probabilidade pelo teste $\mathrm{F}$, sendo as médias dos tratamentos comparadas pelo teste de Tukey.

\section{RESULTADOS E DISCUSSÃO}

Os valores médios dos componentes de produção e da produtividade de grãos de milho, comparando-se as cultivares em cada população, para os espaçamentos de $0,40 \mathrm{~m}$ e $0,80 \mathrm{~m}$, se acham na Tabela 3. Visualiza-se, no espaçamento de $0,40 \mathrm{~m}$ que a cultivar FORT diferiu estatisticamente do AGN 30A00, quando submetido à população de 60.000 plantas ha-1 apenas no componente massa de 1000 grãos, o que pode ter ocorrido em virtude das características de cada cultivar.

Para a população de 70.000 plantas ha ${ }^{-1}$ as diferenças não foram significativas em nenhum dos componentes e também não se constatou significância para a produtividade dentro de cada população, demonstrando que no espaçamento de 0,40 m, essa densidade não foi influenciada pela cultivar. Como nesse espaçamento são fornecidas melhores condições de ambiente, se houvesse alguma diferença seria pelo potencial genético da cultivar, o que não foi verificado.

Para o espaçamento de $0,80 \mathrm{~m}$, as componentes fileiras de grãos e comprimento da espiga diferiram estatisticamente entre

Tabela 3. Componentes da produção e produtividade de dois híbridos cultivados em duas populações, no Sistema Plantio Direto, nos espaçamentos de 0,40 e $0,80 \mathrm{~m}$

\begin{tabular}{|c|c|c|c|c|c|}
\hline Híbrido & $\begin{array}{l}\text { Número de } \\
\text { espigas } \\
\text { Espigas ha-1 }\end{array}$ & $\begin{array}{l}\text { Fileiras de } \\
\text { grãos } \\
\text { fileiras } \\
\text { espiga }^{-1}\end{array}$ & $\begin{array}{c}\text { Comp. } \\
\text { espiga } \\
\text { cm }\end{array}$ & $\begin{array}{c}\text { Massa } 1000 \\
\text { grãos } \\
\mathbf{g}\end{array}$ & $\mathrm{kg} \mathrm{ha}^{-1}$ \\
\hline \multicolumn{6}{|c|}{ Espaçamento $0,40 \mathrm{~m}$} \\
\hline & \multicolumn{5}{|c|}{60.000 plantas ha $^{-1}$} \\
\hline Fort & $59.166,7$ a & $15,0 \mathrm{a}$ & $13,7 \mathrm{a}$ & $303,0 \mathrm{~b}$ & $6.322,7 \mathrm{a}$ \\
\hline \multirow[t]{2}{*}{ AGN30A00 } & $57.500,0 \mathrm{a}$ & $14,0 \mathrm{a}$ & $13,7 \mathrm{a}$ & $340,0 \mathrm{a}$ & $6.714,3 \mathrm{a}$ \\
\hline & \multicolumn{5}{|c|}{70.000 plantas ha- $^{-1}$} \\
\hline Fort & $67.500,0 \mathrm{a}$ & $15,3 \mathrm{a}$ & $13,0 \mathrm{a}$ & $293,0 \mathrm{a}$ & $7.394,4 \mathrm{a}$ \\
\hline AGN30A00 & $69.166,6$ a & $14,7 \mathrm{a}$ & $14,0 \mathrm{a}$ & $303,0 \mathrm{a}$ & $6.994,3 \mathrm{a}$ \\
\hline DMS & $9.631,0$ & 1,0 & 1,1 & 26,0 & $1.258,9$ \\
\hline CV\% & 9,1 & 3,9 & 4,6 & 4,8 & 11,1 \\
\hline \multicolumn{6}{|c|}{ Espaçamento $0,80 \mathrm{~m}$} \\
\hline & \multicolumn{5}{|c|}{60.000 plantas $\mathrm{ha}^{-1}$} \\
\hline Fort & $50.416,7 \mathrm{a}$ & $15,0 \mathrm{a}$ & $13,7 \mathrm{~b}$ & $304,0 \mathrm{a}$ & $6.334,9 \mathrm{a}$ \\
\hline \multirow[t]{2}{*}{ AGN30A00 } & $58.333,3 \mathrm{a}$ & $13,7 \mathrm{~b}$ & $15,0 \mathrm{a}$ & $320,0 \mathrm{a}$ & $7.243,5 \mathrm{a}$ \\
\hline & \multicolumn{5}{|c|}{70.000 plantas ha- ${ }^{-1}$} \\
\hline Fort & $57.083,3 \mathrm{a}$ & $15,0 \mathrm{a}$ & $11,7 \mathrm{~b}$ & $263,0 \mathrm{~b}$ & $3.407,5 \mathrm{~b}$ \\
\hline AGN30A00 & $64.583,3 \mathrm{a}$ & $13,7 \mathrm{~b}$ & $14,7 \mathrm{a}$ & $303,0 \mathrm{a}$ & $7.237,4 \mathrm{a}$ \\
\hline DMS & $9.631,0$ & 1,0 & 1,1 & 26,0 & $1.258,9$ \\
\hline CV\% & 9,1 & 3,9 & 4,6 & 4,8 & 11,1 \\
\hline
\end{tabular}

Médias seguidas de letras iguais em cada população não diferem entre si pelo teste de Tukey a $5 \%$ de probabilidade 
os híbridos nas duas densidades a que foram submetidos sendo que, na população de 70.000 plantas ha ${ }^{-1}$, os efeitos desses dois componentes, além da diferença apresentada pela massa de 1000 grãos, influenciaram na significância para produtividade entre os materiais estudados.

Nota-se que ocorreu efeito da plasticidade da cultura nos componentes fileiras de grãos e comprimento da espiga para os híbridos estudados, fazendo com que houvesse compensação em uma dessas componentes; desta forma, quando a média do número de fileiras de grãos foi menor, o comprimento da espiga foi superior (AGN30A00) e, quando o número de fileiras de grãos foi maior, o comprimento da espiga foi menor (FORT).

Para a componente massa de 1000 grãos atribui-se a diferença no tratamento com 70.000 plantas ha ${ }^{-1}$ às características genéticas do híbrido FORT, somadas a um provável estresse sofrido pela cultivar quando fertilizado em maior densidade no espaçamento de $0,80 \mathrm{~m}$. No experimento de Palhares (2003), notou-se que o genótipo com arquitetura foliar mais aberta cultivado em $0,80 \mathrm{~m}$, na população de 90.000 plantas ha-1, obteve resposta negativa.

Os dados médios dos componentes de produção e produtividade em função da população de plantas, estão na Tabela 4. O rendimento de grãos do híbrido FORT, cultivado em $0,80 \mathrm{~m}$ de distância entre fileiras, teve influência do aumento na densidade de plantas. Na população de 60.000 plantas ha-1 a produtividade foi de $6.334,9 \mathrm{~kg} \mathrm{ha}^{-1}$

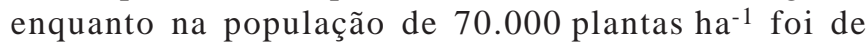
$3.407,5 \mathrm{~kg} \mathrm{ha}^{-1}$, diferindo estatisticamente.

Os componentes que determinaram este efeito foram o comprimento de espigas e a massa de 1000 grãos. A massa individual do grão é produto da duração do período efetivo de enchimento e da taxa de crescimento do grão que, por sua vez, depende de fatores que controlam a oferta de assimilados para o seu pleno enchimento. Segundo Fancelli \& Dourado Neto (2000), este componente pode ser afetado por qualquer tipo de estresse que a planta sofra após o florescimento; assim, é possível que nesse espaçamento o cultivo mais adensado tenha favorecido a competição entre as plantas por radiação solar incidente, nutrientes e água, prejudicando o rendimento (Sangoi et al., 2000).

A maior densidade de plantas não afetou nenhum dos componentes de produção do híbrido AGN 30A00, cultivado no mesmo espaçamento, provavelmente em virtude deste híbrido apresentar arquitetura com folhas mais eretas e menor área foliar, minimizando a competição entre plantas (Almeida et al., 2000).

Para o cultivo dos híbridos no espaçamento de $0,40 \mathrm{~m}$ se observaram diferenças no número de espigas, para ambas as cultivares; este fato não exerceu efeito na produtividade do híbrido FORT, que obteve $6.322,7$ e $7.394,4 \mathrm{~kg} \mathrm{ha}^{-1}$ nas populações de 60.000 e 70.000 plantas ha ${ }^{-1}$, respectivamente.

Na cultivar AGN 30A00, notou-se diferença estatística significativa para o componente massa de 1000 grãos, que se mostrou superior no tratamento com menor população ocorrendo, portanto, compensação desse componente em relação ao menor número de espigas, fazendo com que não se registrasse efeito significativo para a produtividade.
Tabela 4. Componentes da produção e produtividade de duas populações para dois híbridos no Sistema Plantio Direto. Espaçamento 0,80 e 0,40 m

\begin{tabular}{lllccc}
\hline População & $\begin{array}{c}\text { Número de } \\
\text { espigas }\end{array}$ & $\begin{array}{c}\text { Fileiras } \\
\text { de grãos } \\
\text { fileiras }\end{array}$ & $\begin{array}{c}\text { Comp. } \\
\text { espiga }\end{array}$ & $\begin{array}{c}\text { Massa } 1000 \\
\text { grãos }\end{array}$ & Produt. \\
Plantas ha-1 $^{\text {Espigigas ha-1 }}$ & cm & g & kg ha-1 $^{-1}$
\end{tabular}

Espaçamento $0,80 \mathrm{~m}$

\begin{tabular}{lrrrrr}
60.000 & $50.416,7 \mathrm{a}$ & $15,0 \mathrm{a}$ & $13,7 \mathrm{a}$ & $304,0 \mathrm{a}$ & $6.334,9 \mathrm{a}$ \\
70.000 & $57.083,3 \mathrm{a}$ & $15,0 \mathrm{a}$ & $\begin{array}{c}11,7 \mathrm{~b} \\
\text { AGN30A00 }\end{array}$ & $263,0 \mathrm{~b}$ & $3.407,5 \mathrm{~b}$ \\
& & \multicolumn{5}{c}{$\begin{array}{c}\text { Fort } \\
60.000\end{array}$} & $58.333,3 \mathrm{a}$ & $13,7 \mathrm{a}$ & $15,0 \mathrm{a}$ & $320,0 \mathrm{a}$ & $7.243,5 \mathrm{a}$ \\
70.000 & $64.583,3 \mathrm{a}$ & $13,7 \mathrm{a}$ & $14,7 \mathrm{a}$ & $303,0 \mathrm{a}$ & $7.237,4 \mathrm{a}$ \\
DMS & $9.631,0$ & 1,0 & 1,1 & 26,0 & $1.258,9$ \\
CV\% & 9,1 & 3,9 & 4,6 & 4,8 & 11,1 \\
\hline
\end{tabular}

Espaçamento $0,40 \mathrm{~m}$

\begin{tabular}{lrrrrr}
60.000 & $59.166,7 \mathrm{~b}$ & $15,0 \mathrm{a}$ & $\begin{array}{c}\text { Fort } \\
13,7 \mathrm{a}\end{array}$ & $303,0 \mathrm{a}$ & $6.322,7 \mathrm{a}$ \\
70.000 & $67.500,0 \mathrm{a}$ & $15,3 \mathrm{a}$ & $\begin{array}{c}13,0 \mathrm{a} \\
\text { AGN30A00 }\end{array}$ \\
& & \multicolumn{5}{c}{$293,0 \mathrm{a}$} & $7.394,4 \mathrm{a}$ \\
60.000 & $57.500,0 \mathrm{~b}$ & $14,0 \mathrm{a}$ & $13,7 \mathrm{a}$ & $340,0 \mathrm{a}$ & $6.714,3 \mathrm{a}$ \\
70.000 & $69.166,6 \mathrm{a}$ & $14,7 \mathrm{a}$ & $14,0 \mathrm{a}$ & $303,0 \mathrm{~b}$ & $6.994,3 \mathrm{a}$ \\
DMS & $9.631,0$ & 1,0 & 1,1 & 26,0 & $1.258,9$ \\
CV\% & 9,1 & 3,9 & 4,6 & 4,8 & 11,1 \\
\hline
\end{tabular}

Médias seguidas de letras iguais em cada população não diferem entre si pelo teste de Tukey a $5 \%$ de probabilidade

Pode-se verificar, na Tabela 5, que dentre os componentes avaliados apenas o comprimento de espigas da cultivar

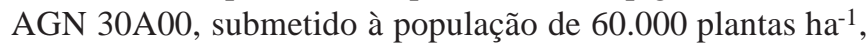
apresentou diferenças entre os espaçamentos porém não refletiu na produtividade.

Tabela 5. Componentes da produção e produtividade de dois híbridos cultivados em dois espaçamentos no Sistema Plantio Direto. População de plantas de 60.000 e 70.000 plantas ha-1 $^{-1}$

\begin{tabular}{|c|c|c|c|c|c|}
\hline Espaçamento & $\begin{array}{l}\text { Número de } \\
\text { espigas }\end{array}$ & $\begin{array}{l}\text { Fileiras } \\
\text { de grãos }\end{array}$ & $\begin{array}{l}\text { Comp. } \\
\text { espiga }\end{array}$ & $\begin{array}{l}\text { Massa } 1000 \\
\text { grãos }\end{array}$ & Produt. \\
\hline m & Espigas ha-1 & $\begin{array}{l}\text { fileiras } \\
\text { espiga }^{-1}\end{array}$ & cm & g & kg ha-1 \\
\hline \multicolumn{6}{|c|}{ População 60.000 plantas ha-1 } \\
\hline & & & Fort & & \\
\hline 0,80 & $50.416,7 \mathrm{a}$ & $15,0 \mathrm{a}$ & $13,7 \mathrm{a}$ & $304,0 \mathrm{a}$ & $6.334,9 \mathrm{a}$ \\
\hline 0,40 & $59.166,7 \mathrm{a}$ & $15,0 \mathrm{a}$ & $\begin{array}{c}13,7 \text { a } \\
\text { AGN30A00 }\end{array}$ & $303,0 \mathrm{a}$ & $6.322,7 \mathrm{a}$ \\
\hline 0,80 & $58.333,3 \mathrm{a}$ & $13,7 \mathrm{a}$ & $15,0 \mathrm{a}$ & $320,0 \mathrm{a}$ & $7.243,5 \mathrm{a}$ \\
\hline 0,40 & $57.500,0 \mathrm{a}$ & $14,0 \mathrm{a}$ & $13,7 \mathrm{~b}$ & $340,0 \mathrm{a}$ & $6.714,3 \mathrm{a}$ \\
\hline DMS & $9.631,0$ & 1,0 & 1,1 & 26,0 & $1.258,9$ \\
\hline CV\% & 9,1 & 3,9 & 4,6 & 4,8 & 11,1 \\
\hline
\end{tabular}

População 70.000 plantas ha $^{-1}$

\begin{tabular}{lccccc}
0,80 & $57.083,3 \mathrm{~b}$ & $15,0 \mathrm{a}$ & $\begin{array}{c}11,7 \mathrm{~b} \\
263,0 \mathrm{~b}\end{array}$ & $3.407,5 \mathrm{~b}$ \\
0,40 & $67.500,0 \mathrm{a}$ & $15,3 \mathrm{a}$ & $\begin{array}{c}13,0 \mathrm{a} \\
\text { AGN30A00 }\end{array}$ & $293,0 \mathrm{a}$ & $7.394,4 \mathrm{a}$ \\
& & & & \\
0,80 & $64.583,3 \mathrm{a}$ & $13,7 \mathrm{~b}$ & $14,7 \mathrm{a}$ & $303,0 \mathrm{a}$ & $7.237,4 \mathrm{a}$ \\
0,40 & $69.166,6 \mathrm{a}$ & $14,7 \mathrm{a}$ & $14,0 \mathrm{a}$ & $303,0 \mathrm{a}$ & $6.994,3 \mathrm{a}$ \\
DMS & $9.631,0$ & 1,0 & 1,1 & 26,0 & 941,2 \\
CV\% & 9,1 & 3,9 & 4,6 & 4,8 & 11,1 \\
\hline
\end{tabular}

Médias seguidas de letras iguais em cada população não diferem entre si pelo teste de Tukey a $5 \%$ de probabilidade 
Destaca-se que a simples redução do espaçamento entre linhas não é garantia de incrementos na produtividade. Trabalhos conduzidos por Forcella et al. (1992), Teasdale (1995), Merotto Júnior et al. (1997) e Westgate et al. (1997) apud Sangoi et al. (2004) não detectaram qualquer benefício da utilização de linhas mais próximas sobre o rendimento de grãos de milho; esses resultados existentes na literatura podem ser atribuídos a diversos fatores, entre os quais se pode citar o tipo de híbrida, população de plantas, as características climáticas da região e o nível de fertilidade do solo, dentre outros (Sangoi et al., 2002).

Ainda na Tabela 5, onde é demonstrado o efeito do espaçamento na população de 70.000 plantas ha-1, se verificou que apenas a cultivar FORT foi influenciada pela redução no espaçamento, nos componentes número de espigas, comprimento de espiga e massa de 1000 grãos, refletindo em diferença significativa na produtividade.

Porter et al. (1997) apud Sangoi et al. (2003), relatam que em situações de alta competição intra-específica por recursos do ambiente, as plantas cultivadas em espaçamentos reduzidos apresentam maior aproveitamento dos recursos limitados; este fato explica o resultado encontrado, uma vez que a cultivar FORT é desfavorecida, quando submetida a alta densidade, sem reduzir o espaçamento, como já verificado.

O aumento da produtividade de grãos, decorrente da redução do espaçamento entre fileiras, é evidente em elevadas populações de plantas já que, em populações elevadas (alta concentração de plantas na linha), a competição entre plantas de milho é maior.

Os resultados médios de produtividade apresentaram significância pelo teste $\mathrm{F}(\mathrm{P}<0,05)$ para a interação espaçamento $\mathrm{x}$ densidade populacional. A Tabela 6 mostra que, na análise conjunta das cultivares, o rendimento de grãos de milho foi significativamente influenciado pelo espaçamento entre linhas quando submetido a densidade de semeadura de 70.000 plantas ha ${ }^{-1}$, sendo superior no tratamento com menor espaçamento, e pela população, quando cultivada no espaçamento de $0,80 \mathrm{~m}$. O incremento na produtividade verificado com a redução do espaçamento na maior população, confirma as observações de Hoeft (2003), de que o benefício das linhas mais estreitas é mais pronunciado em populações mais elevadas.

Tabela 6. Produtividade de milho em função do espaçamento e da população de plantas, em Alagoas no Sistema Plantio Direto

\begin{tabular}{ccc}
\hline População & \multicolumn{2}{c}{ Espaçamento } \\
\cline { 2 - 3 } plantas ha-1 $^{-1}$ & $\mathbf{0 , 8 0} \mathbf{~ m}$ & $\mathbf{0 , 4 0 ~ \mathbf { ~ }}$ \\
60.000 & $6.782,2 \mathrm{Aa}$ & $6.518,5 \mathrm{Aa}$ \\
70.000 & $5.322,5 \mathrm{Bb}$ & $7.194,4 \mathrm{Aa}$ \\
\hline
\end{tabular}

Médias seguidas de letras iguais, maiúsculas na coluna e minúsculas na linha, não diferem entre si pelo teste de Tukey a $5 \%$ de probabilidade Coeficiente de variação: $11,1 \%$ e DMS: 890,2

\section{CONCLUSÕES}

1. A redução do espaçamento como prática isolada não proporciona incremento no rendimento de grãos, para as cultivares testadas.
2. O aumento na densidade de plantas, também como prática isolada, não aumenta os rendimentos ou, até mesmo, os prejudica.

3. A associação das práticas de manejo, redução no espaçamento e aumento na população de plantas, resulta em significativo incremento na produtividade de grãos do híbrido FORT.

\section{LITERATURA CITADA}

Almeida, M. L.; Meroto Júnior, A.; Sangoi, L.; Ender, M.; Guigdolin, A. F. Incremento na densidade de plantas: Uma alternativa para aumentar o rendimento de grãos de milho em regiões de curta estação estival de crescimento. Ciência Rural, Santa Maria, v.30, n.1. p.23-29, 2000.

Duvick, D. N.; Cassan, K. G. Post-green revolution trends in yield potential of temperate maize in the North-Central United States. Crop Science, Madison, v.39, n.6, p.16221630, 1999.

EMBRAPA - Empresa Brasileira de Pesquisa Agropecuária. Sistema brasileiro de classificação de solos. Brasília: EMBRAPA, 1999. 412p.

Fancelli, A. L. Plantas alimentícias: Guia para aula estudos e discussão. Piracicaba: ESALQ/USP, 1986. 131p.

Fancelli, A. L.; Dourado Neto, D. Produção de milho. Guaíba: Agropecuária, 2000. 360p.

Hoeft, R. G. Desafios para obtenção de altas produtividade de milho e de soja nos EUA. Informações Agronômicas, Piracicaba, v.104, p.1-4, 2003.

Kasperbauer, M. J.; Karlen, D. L. Plant spacing and reflected farred light effects on phytochrome-regulated photosynthate allocation in corn seedlings. Crop Science, Madison, v.34, n.6, p.1564-1569, 1994.

Palhares, M. Distribuição e população de plantas e produtividade de grãos de milho. Piracicaba: ESALQ/USP, 2003. 90p. Dissertação Mestrado

Sangoi, L. Understanding plant density effects on maize growth and development: An important issue to maximize grain yield. Ciência Rural, Santa Maria, v.31, n.1, p.159-168, 2001.

Sangoi, L.; Almeida, M. L.; Gracietti, M.; Bianchet, P.; Horn, D. Sustentabilidade do colmo em híbridos de milho de diferentes épocas de cultivo em função da densidade de plantas. Revista de Ciências Agroveterinárias, Lages, v.1, n.2, p.1, 2002.

Sangoi, L.; Ender, M.; Guidolin, A. F.; Bogo, A.; Kothe, D. M. Incidência e severidade de doenças de quatro híbridos de milho cultivados em diferentes densidades de planta. Ciência Rural, Santa Maria, v.30, n.1, p.17-21, 2000.

Sangoi, L.; Silva, P. R. F.; Argenta, G. Arranjo espacial e plantas e milho: Como otimiza-lo para maximizar o rendimento. In: Congresso Nacional de Milho e Sorgo, 25, 2004. Anais... Cuiabá: ASBMS, 2004, p.150-159.

Sangoi, L.; Silva, P. R. F.; Argenta, G.; Horn, D. Bases morfo-fisiológicas para aumentar a tolerância de cultivares de milho a altas densidades de plantas. In: Reunião Técnica Catarinense de Milho e Feijão, 4, 2003, Anais... Lages: CAV-UDESC, 2003, p.19-24.

R. Bras. Eng. Agríc. Ambiental, v.12, n.1, p.69-74, 2008. 
Silva, E. T. da; Albuquerque, A. W.; Santos, J. R.; Santos, E. A.; Pereira, F. R. S.; Cruz, S. C. S.; Pereira, R. G.; Feitosa, E. M. F.; Lima M. F. P. Produção da cultura do milho influenciada por diferentes sistemas de manejo do solo. In: Congresso Brasileiro de Ciência do Solo, 30, 2005 Anais... Recife: SBCS, 2005. CD Rom. Silva, P. R. F.; Argenta, G.; Sangoi, L. Fatores determinantes da escolha da densidade de plantas em milho. In: Reunião Técnica Catarinense de Milho e Feijão, 4, 2003. Anais... Lages: CAV-UDESC, 2003, p.25-29.
Teodoro, I. Avaliação energética e hídrica no desenvolvimento da cultura do milho irrigado, na Região de Rio Largo, AL. Rio Largo: UFAL, 2003. 108p. Dissertação Mestrado

Tollenaar, M.; Lee, E.Yield potential, yield stability and stress tolerance in maize. Field Crops Research, Amsterdan, v.75, n.1, p.161-169. 2002.

Tollenaar, M; Wu, J. Yield improvement in temperate maize is atributable to greater stress tolerance. Crop Sciense, Madison, v.39, n.6, p.1597-1604, 1999. 